\title{
Review \\ The place for short-acting opioids: special emphasis on remifentanil
}

\author{
Wolfram Wilhelm ${ }^{1}$ and Sascha Kreuer ${ }^{2}$
}

\begin{abstract}
${ }^{1}$ Department of Anesthesiology and Intensive Care Medicine, Klinikum St.-Marien-Hospital Lünen, 44534 Lünen, Altstadtstrasse, Germany ${ }^{2}$ Department of Anesthesiology, Intensive Care and Pain Medicine, University of Saarland, 66421 Homburg/Saar, Kirrberger Strasse, Germany
\end{abstract}

Corresponding author: Wolfram Wilhelm, wolfram.wilhelm@smh-online.de

Published: 14 May 2008

This article is online at http://ccforum.com/content/12/S3/S5

(c) 2008 BioMed Central Ltd
Critical Care 2008, 12(Suppl 3):S5 (doi:10.1186/cc6152)

of pain medication, and opioids are most frequently administered in this setting. Some years ago, a European investigation into analgesia and sedation in the ICU [2] revealed that the drugs most commonly used for analgesia were morphine (33\%), fentanyl (33\%), and sufentanil (24\%), and also demonstrated substantial differences in analgesic practice throughout Europe.

\section{Morphine}

Opioids are the mainstay of analgesia in the ICU. However, these drugs have a number of adverse effects, and this is especially true for morphine. Although all opioids may lead to respiratory depression, it is important to bear in mind that the morphine-6-glucuronide metabolite is more potent than morphine itself, and that accumulation can occur, especially in patients with renal impairment [3]. Typical adverse effects of morphine include histamine release, pruritus, and, in particular, constipation. Regarding the various national guidelines on the use of sedatives and analgesics in critically ill adults, morphine use is included in the recommendations of the American College of Critical Care Medicine (ACCM) and of the Society of Critical Care Medicine (SCCM) [4]. In contrast, the German Society of Anaesthesiology and Intensive Care Medicine opted not to recommend the use of morphine when opioids are needed for longer than 24 hours [5].

\section{Fentanyl, alfentanil and sufentanil}

These agents are synthetic opioids of the 4-anilidopiperidine group and they are commonly used in the operating room. These opioids also undergo hepatic metabolism, and their continuous infusion can lead to accumulation as well as prolonged drug effects. This is especially so in critically ill patients, in whom drug clearance may be substantially reduced because of illness, organ dysfunction, or concomitant therapy. Therefore, use of fentanyl, alfentanil, and sufentanil

$\mathrm{ICU}=$ intensive care unit; $\mathrm{RA}=$ remifentanil acid. 
as well as morphine in ICU patients is always accompanied by concerns regarding drug accumulation, which potentially can lead to prolonged respiratory depression and delayed and unpredictable recovery. Fentanyl is available worldwide, but alfentanil is not commonly used in North America [4], and neither alfentanil nor sufentanil are licensed for use in ICU patients in many countries.

When these opioids are compared, alfentanil is the drug with the most rapid onset of action and the shortest duration of effect. However, alfentanil is a substrate for different cytochrome P4503A enzymes, and its metabolism and offset of effect can underly interindividual variability due to polymorphic enzyme expression and can markedly be inhibited by different drugs, including antibiotics and antifungal medication [6]. Thus, although single bolus injections of alfentanil are short acting, the effects of an infusion of alfentanil in ICU patients are much less predictable, and so this drug is not the ideal short-acting opioid for use in the ICU.

\section{Defining the place for a short-acting opioid}

Since intensivists identified the potentially devastating impact of accumulation of analgesic and sedative drugs on patient outcomes, various attempts have been made to limit such accumulation. Means include daily interruption of infusion of sedatives and analgesics [7], intermittent bolus injections rather than continuous infusions [8], and selecting ventilatory support that permits more spontaneous than controlled ventilation [9], among many others. These techniques are discussed in detail in the other reviews included in this supplement.

However, these techniques at best only limit the effects of drug accumulation, but they do not solve the problem itself. Therefore, a totally different approach is needed, one that involves a drug that undergoes rapid and complete metabolism, independent of the duration of infusion or any organ insufficiency.

\section{Remifentanil: pharmacology}

Remifentanil is a potent selective $\mu$-opioid receptor agonist and was first approved for use as an analgesic agent during induction and maintenance of general anesthesia in 1996. In 2002 remifentanil received approval from the European Medicines Agency for provision of analgesia for a duration of up to 3 days in mechanically ventilated ICU patients, aged 18 years or older.

Like fentanyl, alfentanil, and sufentanil, remifentanil is a 4anilidopiperidine $\mu$-opioid analgesic. However, in contrast to fentanyl and its congeners, remifentanil is completely metabolized by unspecific esterases. In principle, esterases are enzymes that break down esters into their alcohol and acid components. The term 'unspecific' means that one enzyme not only catalyzes a specific reaction but is also able to break down other ester linkages, for example, that of
Figure 1

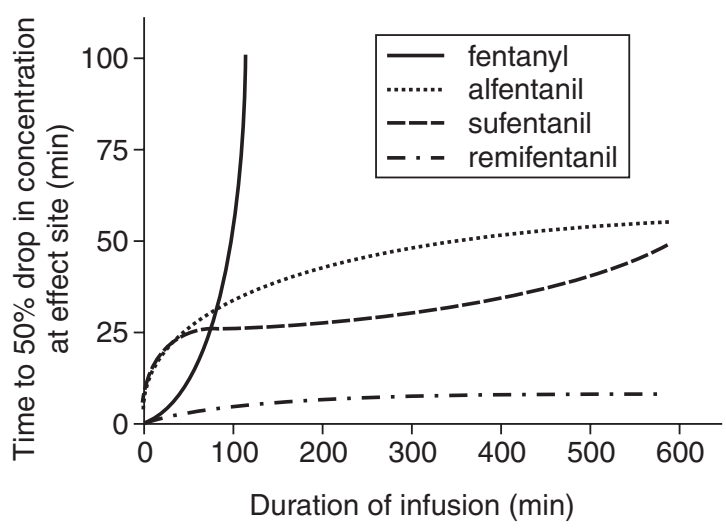

Context-sensitive half-times of remifentanil and the other 4-anilidopiperidine opioids. Remifentanil has a context-sensitive half-time of 3 to 4 minutes, regardless of the duration of infusion, whereas continuous infusion of the other opioids results in accumulation and considerable prolongation of effect, making these opioids intermediate-acting or long-acting agents, depending on the duration of infusion. Figure adapted with permission from Egan TD, Lemmens HJ, Fiset $P$, Hermann DJ, Muir KT, Stanski DR, Shafer SL: The pharmacokinetics of the new short-acting opioid remifentanil (GI87084B) in healthy adult male volunteers. Anesthesiology 1993, 79:881-892.

remifentanil. Because unspecific esterases are involved in multiple steps in the metabolism of the living human cell, no ICU disease or organ failure has yet been identified that can cause reduced breakdown of remifentanil.

The major breakdown product of remifentanil is remifentanil acid (RA), which is a relatively inactive carboxylic acid metabolite with only $1 / 300$ to $1 / 4,600$ of the activity of remifentanil $[10,11]$. In a rat model, the low in vivo potency of RA was explained by a low affinity to the $\mu$-opioid receptor in combination with a poor brain penetration [12]. At least $88 \%$ of the RA dose is eliminated in the urine in healthy, renally nonimpaired adults, with a mean terminal elimination half-life ranging from 88 to 137 minutes after bolus doses of remifentanil of 2 to $30 \mu \mathrm{g} / \mathrm{kg}$ [13] (note that these bolus doses by far exceed licensed use). The clearance of RA is reduced in patients with impaired renal function, and the halflife of RA increases to 14 to 32 hours in these patients $[14,15]$.

Because of its unique pharmacokinetic profile, remifentanil is characterized by a rapid and uniform clearance and a highly predictable onset and offset of effect [11]. Remifentanil has a terminal half-life of approximately 10 to 20 minutes [16], and its context-sensitive half-time is 3 to 4 minutes, regardless of the duration of infusion [10]. In contrast, continuous infusions of the other 4-anilidopiperidine opioids result in accumulation and considerable prolongation of effect with increased duration of infusion [10], making these opioids intermediate- 


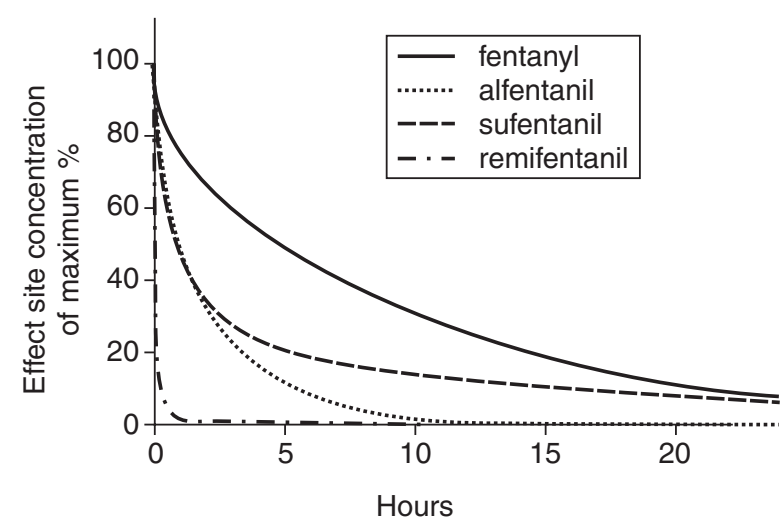

Decline of effect site concentrations of different opioids after 24 hours of infusion. The findings are expressed as percentage of the individual maximum effect site concentration. This figure was calculated using Stanpump simulation software (by Shafer S, University of Stanford, CA, USA) for a female individual (age 80 years, height $170 \mathrm{~cm}$, body weight $80 \mathrm{~kg}$ ) and the following infusion rates: remifentanil $0.15 \mu \mathrm{g} / \mathrm{kg}$ per minute, sufentanil $1 \mu \mathrm{g} / \mathrm{kg}$ per hour, alfentanil $1.5 \mathrm{mg} / \mathrm{hour}$, and fentanyl $0.2 \mathrm{mg} /$ hour.

acting or long-acting agents during prolonged infusion (Figures 1 and 2).

\section{First experiences with remifentanil in the intensive care unit}

Although remifentanil is not licensed for applications for longer than 3 days, several of the reports reviewed here and in other reviews included in this supplement have addressed its use for longer periods.

The first experiences with the use of remifentanil in ICU patients were reported shortly after remifentanil became available for use in the operating room. In a case series of six patients, Evans and Park [17] reported successful use of remifentanil for analgesia and sedation during mechanical ventilation for 3 to 33 days. The infusion rate ranged from 0.08 to $0.43 \mu \mathrm{g} / \mathrm{kg}$ per minute (modal values), and all patients exhibited signs of recovery within 10 minutes of stopping the remifentanil infusion. Similar findings were reported by Soltész and coworkers [18], who examined the recovery of ICU patients after trauma or major surgery. After 24 hours of remifentanil infusion at a mean rate of $0.18 \mu \mathrm{g} / \mathrm{kg}$ per minute and propofol infusion at $2.1 \mathrm{mg} / \mathrm{kg}$ per hour, all patients could follow simple commands as early as 10 minutes after stopping both infusions. In another study conducted in 46 ICU patients aged $62.8 \pm 15.4$ years [19], the mean duration of remifentanil infusion was 9.8 hours and the mean dosage was $0.14 \pm 0.08 \mu \mathrm{g} / \mathrm{kg}$ per minute. Extubation was achieved within 15 minutes of stopping the infusion in 31 patients
Figure 3

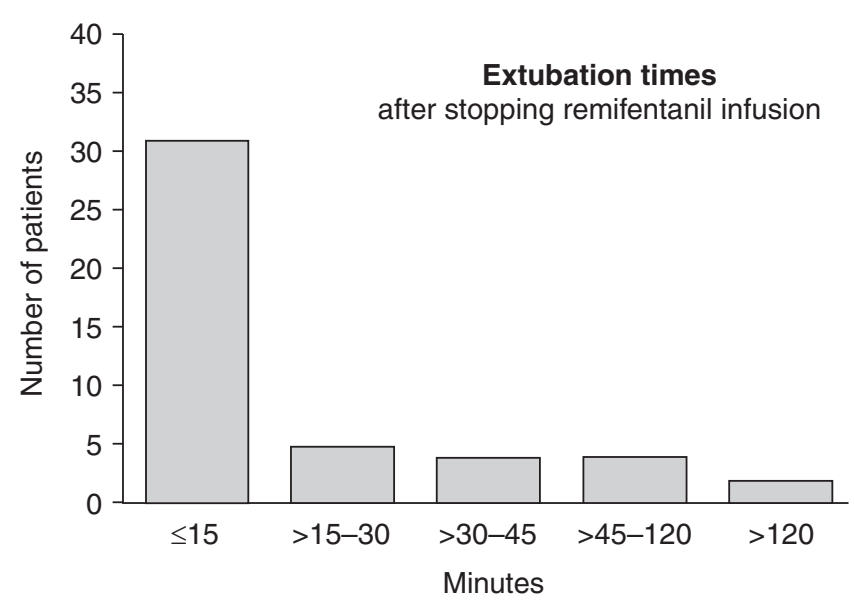

Extubation times after remifentanil infusion. Shown are extubation times in 46 intensive care unit patients after sedation with a remifentanil infusion (mean duration 9.8 hours, mean dosage $0.14 \pm 0.08 \mu \mathrm{g} / \mathrm{kg}$ per minute). Two-thirds of all patients could be extubated within 15 minutes and $87 \%$ within 45 minutes after cessation of remifentanil infusion. Figure adapted with permission from: Wilhelm W, Dorscheid E, Schlaich N, Niederprüm, Deller D: The use of remifentanil in critically ill patients. Clinical findings and early experience. Anaesthesist 1999, 48:625-629. (C) Springer.

(67\%) and within 45 minutes in 40 (87\%); only in two of the 46 patients did recovery require longer than 120 minutes (Figure 3).

\section{Comparative studies of remifentanil and other opioids}

Within the ICU, remifentanil has been compared with various other opioids in the management of critically ill patients requiring mechanical ventilation.

Dahaba and colleagues [20] evaluated 40 mechanically ventilated patients who received a blinded infusion of either remifentanil $0.15 \mu \mathrm{g} / \mathrm{kg}$ per minute or morphine $0.75 \mu \mathrm{g} / \mathrm{kg}$ per minute. Initially, the opioid infusion was titrated to reach an optimal level of sedation (defined as Sedation Agitation Scale score of 4), and a midazolam infusion was added only if further sedation was deemed necessary. Although adverse events were seldom and comparable in both groups, fewer infusion rate adjustments were necessary in the remifentanil group, and the percentage of time spent in optimal sedation was greater for remifentanil than for morphine. Most important, the mean duration of mechanical ventilation was significantly shorter with remifentanil ( $14.1 \pm 2.8$ hours) than with morphine (18.1 \pm 3.4 hours), and the same was true for extubation times ( $17 \pm 6$ minutes versus $73 \pm 7$ minutes) and intervals from extubation until ICU discharge $(20.7 \pm 3.7$ hours versus $41.7 \pm 8.6$ hours). 
In another randomized, double-blinded study, Müllejans and coworkers [21] examined 152 mechanically ventilated patients who received either remifentanil $(0.15 \mu \mathrm{g} / \mathrm{kg}$ per minute) or fentanyl ( $1.5 \mu \mathrm{g} / \mathrm{kg}$ per hour). Opioid infusion rates could be adjusted to reach an optimal level of sedation (defined as Sedation Agitation Scale score of 4), and propofol $0.5 \mathrm{mg} / \mathrm{kg}$ per hour was added when required. The mean percentages of time spent in optimal sedation were similar in both groups ( $88 \%$ to $89 \%$ ), and only $35 \%$ of patients in the remifentanil group and $40 \%$ of patients in the fentanyl group needed additional propofol. Among those patients, however, the required median total propofol dose was nearly twice as high with fentanyl $(683 \mathrm{mg}$ ) as with remifentanil (378 $\mathrm{mg}$, $P=0.065)$. Of note, recovery times were similar in both groups (1.1 to 1.3 hours), probably because of the dosing algorithm and the high frequency of monitoring and dosage adjustments, which clearly prevented over-sedation in this study.

In another study, Müllejans and colleagues [22] evaluated 80 patients who were mechanically ventilated for 12 to 72 hours after having undergone cardiac surgery. Patients received either remifentanil $(0.1$ to $1 \mu \mathrm{g} / \mathrm{kg}$ per minute [exceeding the maximum licensed dose of $0.74 \mu \mathrm{g} / \mathrm{kg}$ per minute]) and propofol ( 0.5 to $4.0 \mathrm{mg} / \mathrm{kg}$ per hour, added only in the case of insufficient sedation at maximal remifentanil dose), or fentanyl ( 1.0 to $7.0 \mu \mathrm{g} / \mathrm{kg}$ per hour) and midazolam (0.02 to $0.2 \mathrm{mg} / \mathrm{kg}$ per hour). Intervals from ICU admission to extubation and to eligibility for discharge from the ICU were significantly shorter after remifentanil/propofol (20.7 \pm 5.2 hours and $46.1 \pm 22.0$ hours) than after fentanyl/midazolam (24.2 \pm 7.0 hours and $62.4 \pm 27.2$ hours, $P<0.05$ ), whereas overall ICU costs were equal in the two groups, at about $€ 1,700 /$ patient.

Baillard and colleagues [23] compared remifentanil (starting dose $0.17 \mu \mathrm{g} / \mathrm{kg}$ per minute) and sufentanil (starting dose $0.125 \mu \mathrm{g} / \mathrm{kg}$ per hour), both combined with midazolam (starting dose $0.1 \mathrm{mg} / \mathrm{kg}$ per hour), for long-term sedation in 41 critically ill adult patients requiring mechanical ventilation in the ICU. Weaning times were significantly shorter after remifentanil/midazolam (median 22 hours, interquartile range 12 to 53 hours) than after sufentanil/midazolam (median 96 hours, interquartile range 47 to 142 hours). It must be emphasized that the midazolam doses used in this investigation were relatively high, and this may in part explain the long weaning times in both groups, especially with remifentanil.

\section{Remifentanil for neurosurgical and neurotrauma patients}

In patients with traumatic brain injury it has been demonstrated that remifentanil can provide effective sedation during transient painful procedures (for example, endotracheal suctioning and physiotherapy), and no significant changes in mean arterial blood pressure, intracranial pressure, or cerebral blood flow velocity were observed [24]. In another study of remifentanil in severely head injured patients [25], reduction in coughing due to endotracheal suctioning was dose dependent, but most patients needed vasopressors to maintain cerebral perfusion pressure.

One of the most important issues in neuroanesthesia and neurocritical care is neurologic assessment. Therefore, cessation of analgesic and sedative infusions should be accompanied by rapid and predictable awakening, thus allowing clear differentiation between brain dysfunction and over-sedation. Two studies have been conducted $[26,27]$ that compared remifentanil with fentanyl or morphine in neurologic ICU patients.

In a randomized multicenter study, Karabinis and coworkers [26] investigated mechanically ventilated patients who had suffered acute brain injury or had undergone neurosurgery. A total of 84 patients received remifentanil, with a median weighted mean infusion rate of $0.26 \mu \mathrm{g} / \mathrm{kg}$ per minute, combined with propofol (1.93 $\mathrm{mg} / \mathrm{kg}$ per hour) during days 1 to 3 and then with midazolam $(0.18 \mathrm{mg} / \mathrm{kg}$ per hour) on days 4 and 5 . A second group of patients received a hypnoticbased sedation with propofol on days 1 to 3 , followed by midazolam on days 4 and 5 , combined with either fentanyl ( $n=37)$ or morphine $(n=40)$ according to routine clinical practice. When fentanyl was used for analgesia, the median weighted mean infusion rates were $3.6 \mu \mathrm{g} / \mathrm{kg}$ per hour for fentanyl, $2.49 \mathrm{mg} / \mathrm{kg}$ per hour for propofol, and $0.11 \mathrm{mg} / \mathrm{kg}$ per hour for midazolam. With morphine, the respective infusion rates were $0.1 \mathrm{mg} / \mathrm{kg}$ per hour for morphine, $2.30 \mathrm{mg} / \mathrm{kg}$ per hour for propofol, and $0.13 \mathrm{mg} / \mathrm{kg}$ per hour for midazolam. Patients were closely scored to achieve optimal pain relief and sedation. Mean neurologic assessment times were significantly shorter with remifentanil ( 0.41 hours) than with fentanyl ( 0.71 hours) or with morphine (0.82 hours), and patients were extubated significantly faster after remifentanil (1.0 hour; median time from the start of the extubation process until actual extubation) than after morphine (1.93 hours), whereas no difference was observed between remifentanil and fentanyl (0.68 hours). Furthermore, neurological function assessment was judged excellent or very good by $78 \%$ of those using remifentanil, but only by $25 \%$ of those using fentanyl and by $8 \%$ using morphine.

In a retrospective study conducted by Bauer and coworkers [27], 60 patients were enrolled who were undergoing supratentorial brain tumor surgery. General anesthesia as well as ICU sedation consisted of either remifentanil/propofol or fentanyl/midazolam. On the ICU, analgesic and sedative infusions were dosed to reach a Ramsay Sedation Scale score of 4 with remifentanil 0.1 to $0.2 \mu \mathrm{g} / \mathrm{kg}$ per minute and propofol 0.5 to $3 \mathrm{mg} / \mathrm{kg}$ per hour, or with fentanyl 0.03 to $0.2 \mathrm{mg} /$ hour and midazolam 2 to $12 \mathrm{mg} /$ hour. Demographic data and the duration of drug administration were comparable for the remifentanil/propofol (528 \pm 382 minutes) 


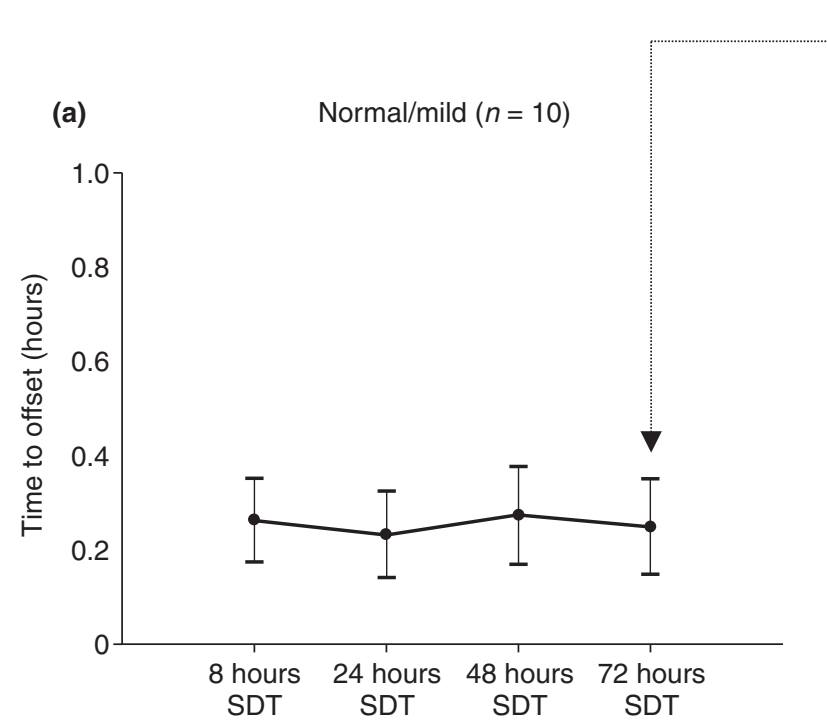

Mean time difference of about 17 minutes

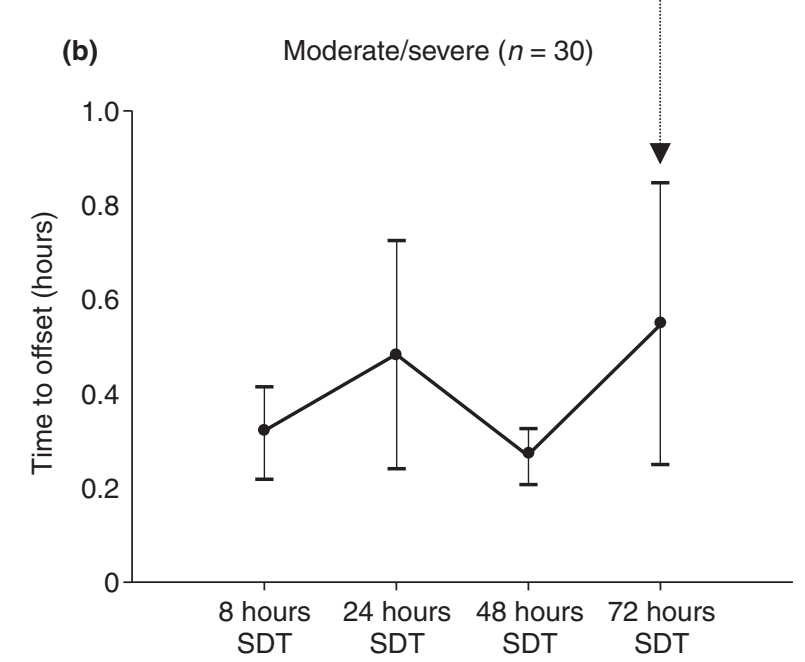

Times to offset of opioid effect after down-titration of remifentanil. Shown are times to offset of opioid effect after scheduled down-titrations (SDT) of remifentanil at $8,24,48$, and 72 hours of infusion in (a) 10 adult intensive care unit patients with normal or mildly impaired renal function and (b) 30 patients with moderate or severe renal impairment with a mean creatinine clearance of $14.7 \mathrm{ml} / \mathrm{minute}$. Offset times were more variable and statistically significantly longer in the renal impairment group (b). However, the time differences between the groups were only in the order of minutes and without clinical importance (about 17 minutes longer [mean] in the renal impairment group after 72 hours of remifentanil infusion). Adapted with permission from Breen and coworkers [30].

and the fentanyl/midazolam (548 \pm 360 minutes) groups. Mean extubation times were significantly shorter after remifentanil/propofol (47 minutes) than after fentanyl/midazolam (481 minutes), and the length of stay in the ICU was significantly reduced (1.8 days versus 3.7 days). As a result of prolonged unconsciousness and consequent inability to conduct a neurologic assessment, a brain computed tomography scan was performed in three patients who had received fentanyl/midazolam to exclude neurosurgical complications.

\section{Impact of organ dysfunction}

Multiple organ dysfunction or failure may complicate the course of many critically ill patients and must therefore be considered when analgesics and sedatives are valued for use on the ICU. Since remifentanil is metabolised organ-independently by unspecific esterases, organ dysfunctions do not alter remifentanil pharmacokinetics, and this has especially been proven for renal and hepatic impaiment [14,28,29]. However, although remifentanil is completely metabolized, its main metabolite, RA, is renally excreted. Although RA has only $1 / 300$ to $1 / 4,600$ of the activity of remifentanil $[10,11]$, it was nevertheless necessary to exclude the possibility of prolonged $\mu$-opioid effect. This was done in a comparative study of 10 adult ICU patients with normal or mildly impaired renal function and 30 patients with moderate or severe renal impairment with a mean creatinine clearance of $14.7 \mathrm{ml} /$ minute
$[15,30]$. All patients received remifentanil for up to 72 hours, with the dosage starting with 0.1 to $0.15 \mu \mathrm{g} / \mathrm{kg}$ per minute. Mathematical modeling revealed that remifentanil pharmacokinetics were not significantly influenced by renal dysfunction, but in patients with moderate or severe renal impairment RA clearance was reduced to about $25 \%$ of normal values [15]. The metabolic ratio increased by 8 -fold in the moderate/ severe group of renal dysfunction relative to the normal/mild group, predicting average RA concentrations at steady state more than 100-fold those of remifentanil in patients with moderate/severe renal impairment [15]. Furthermore, based on pharmacokinetic modelling, it was estimated that a remifentanil infusion of $0.15 \mu \mathrm{g} / \mathrm{kg}$ per minute for up to 15 days would not result in RA concentrations that would prolong opioid effects to a clinically significant degree [15]. In the same type of patients, pharmacodynamic effects were studied using scheduled down-titrations at $8,24,48$, and 72 hours of infusion [30]. In this analysis the interval to offset of opioid effect was more variable and statistically significantly longer in the group of patients with moderate or severe renal impairment. However, the time differences between groups were of the order of minutes and were not clinically important (about 17 minutes longer in the group of patients with moderate or severe renal impairment after 72 hours of remifentanil infusion; Figure 4). In summary, remifentanil can be used to sedate ICU patients with severe renal dysfunction, and dosage adjustments are not required. 
With regard to hepatic function, it has been demonstrated that the pharmacokinetics of remifentanil and RA do not significantly differ between patients with hepatic impairment and healthy volunteers, so no dose adjustments are necessary for hepatic impairment [28,29]. However, Dershwitz and colleagues [28] have demonstrated that individuals with severe hepatic impairment may be more sensitive to the ventilatory depressant effects of remifentanil. Because of its organ-independent metabolism, remifentanil appears to be the ideal agent for sedation of patients with severe liver disease, but its increased ventilatory depressant effect must be taken into consideration, for example, when intubated ICU patients are allowed to breathe spontaneously.

\section{Analgesia-based versus hypnotic-based sedation}

Because of its pharmacologic properties, remifentanil allows a complete re-design of ICU sedation, away from a 'traditional' hypnotic-based regimen to an analgesic-based technique, with the objective being to achieve an awake and pain-free ICU patient. This concept is called 'analgesia-based sedation' [31,32].

Park and coworkers [32] compared 111 patients receiving hypnotic-based sedation (mainly midazolam and propofol) with 96 patients managed using an analgesia-based technique (mainly remifentanil) during two consecutive 12-week periods. About one-third of the remifentanil patients (37\%) required no additional hypnotic, and in the remaining patients the necessary amount of propofol was reduced. Moreover, the number of patients with satisfactory levels of sedation during synchronized intermittent mandatory ventilation was significantly higher in the analgesia-based sedation group.

Breen and colleagues [31] investigated 105 ICU patients requiring mechanical ventilation for up to 10 days. In the analgesia-based group $(n=57)$ patients received remifentanil starting with 0.1 to $0.15 \mu \mathrm{g} / \mathrm{kg}$ per minute, and midazolam could be added if needed once the remifentanil dosage had surpassed $0.2 \mu \mathrm{g} / \mathrm{kg}$ per minute; at remifentanil levels of $0.3 \mu \mathrm{g} / \mathrm{kg}$ per minute or greater, midazolam boluses were used for sedation. In the conventional hypnotic-based group, 48 patients received midazolam, and fentanyl or morphine were added as needed. The time from start of study drug treatment to extubation was significantly shorter with remifentanil than in the hypnotic-based group (94 hours versus 147.5 hours [data are 75 th centiles]), and the same was true for time from weaning to extubation ( 0.9 hours versus 27.5 hours [data are 75 th centiles]). Of note, remifentanil was infused for up to 10 days, and between days 3 and 10 there were no signs of development of tolerance.

\section{Possible concerns surrounding use of remifentanil}

Remifentanil has in general exhibited good tolerability in ICU patients, and hypotension, bradycardia, and nausea have been the adverse events most frequently reported in major clinical trials in mechanically ventilated critically ill patients $[21,26]$. In a study conducted in cardiac surgical patients [22] the total numbers of adverse events were similar with remifentanil/propofol and with midazolam/fentanyl. However, although in the remifentanil/propofol group significantly more drug-related events were observed (including shivering and pain), respiratory insufficiency only occurred with midazolam/ fentanyl in three of the 39 patients and did not occur with remifentanil [22]. Other possible adverse events that have been reported with remifentanil, primarily in the anesthesia literature, are thoracic and muscle rigidity and shivering [33]. Thoracic and muscle rigidity may occur when higher doses of a rapid-onset opioid are injected (for example, a remifentanil bolus dose of $1 \mu \mathrm{g} / \mathrm{kg}$ or more), and this may lead to severe problems with mask ventilation or pressure-controlled ventilation. Therefore, remifentanil bolus doses should be limited to $0.5 \mu \mathrm{g} / \mathrm{kg}$ or omitted, and a muscle relaxant may be used if ventilatory support is needed immediately. The Summary of Product Characteristics (SmPC) for remifentanil states that "bolus doses are not recommended in the intensive care setting".

The possible development of tolerance has been another issue of concern with the use of remifentanil in ICU patients. Tolerance phenomena can occur with all opioids, but even with a prolonged remifentanil application (up to 10 days) the weighted mean infusion rate of remifentanil rose only slightly until day 3 and then was constant until day 10 [31].

With discontinuation of remifentanil the possible onset of pain necessitates an individualized approach to pain management in ICU patients, for instance, the application of a longer acting opioid (for example, 5 to $10 \mathrm{mg}$ morphine or 3 to $7.5 \mathrm{mg}$ piritramide about 30 minutes before the remifentanil infusion is turned off), possibly combined with a nonopioid analgesic. (Piritramide is a synthetic opioid for postoperative pain therapy with a mean duration of action of 4 to 6 hours that is used in several European countries [for population pharmacokinetics, see Bouillon and coworkers [34].) In addition, use of a longer acting $\mu$-opioid analgesic will reduce the probability of shivering, which may occur after use of remifentanil. However, the individual level of pain may differ substantially between a patient with pneumonia-induced respiratory insufficiency and a trauma victim, emphasizing the need for individualized treatment.

\section{Remifentanil in clinical practice}

To administer remifentanil in mechanically ventilated intensive care patients in accordance with its licence (also see the $\mathrm{SmPC}$ ), the following sequence may help to structure the process:

1. Conduct a clinical evaluation of the patient.

2. Initiate a remifentanil infusion at an adequate dosage. The recommended starting dose is between 0.1 and 
$0.15 \mu \mathrm{g} / \mathrm{kg}$ per minute, which is about 0.4 to $0.6 \mathrm{mg} / \mathrm{hour}$ for a $70 \mathrm{~kg}$ patient.

3. Titrate remifentanil in increments of $0.025 \mu \mathrm{g} / \mathrm{kg}$ per minute to achieve the desired level of analgesia. When titrating remifentanil to the individual patient need, a period of at least 5 minutes should be allowed between dose adjustments.

4. If a dosage of $0.2 \mu \mathrm{g} / \mathrm{kg}$ per minute remifentanil is reached and further sedation is necessary, add a hypnotic agent.

5. Adapt the required remifentanil and hypnotic dosage to the individual patient's needs at any given time.

6. Because of the rapid offset of action of remifentanil, no residual opioid activity will be present within 5 to 10 minutes after discontinuation, regardless of the duration of infusion. Therefore, careful planning of the transition to longer acting analgesia is necessary (for example, longer acting opioids should be given at an appropriate dose before discontinuation of remifentanil).

7. If the patient is ready for weaning, then titrate the remifentanil infusion down in adequate steps (see SmPC for details). This will circumvent the possibility that patients might experience discomfort and become agitated when remifentanil is abruptly discontinued.

8. Analgesia and sedation should be monitored closely during the entire procedure. Therefore, the development of standard operating procedures by each individual clinical department is recommended.

In our department it is our practice in most patients to begin with a combination of remifentanil and propofol $2 \%$ [33]. We dilute $5 \mathrm{mg}$ remifentanil in $50 \mathrm{ml}$ saline $0.9 \%$, resulting in a concentration of $100 \mu \mathrm{g} / \mathrm{ml}$. At arrival of the patient in the ICU, both the remifentanil and the propofol syringe pumps are started at 4 to $6 \mathrm{ml} /$ hour $(6 \mathrm{ml} /$ hour of the remifentanil infusion is a little less than $0.15 \mu \mathrm{g} / \mathrm{kg}$ per minute in the $70 \mathrm{~kg}$ patient; $6 \mathrm{ml} /$ hour propofol $2 \%$ is a little less than $2 \mathrm{mg} / \mathrm{kg}$ per hour in the $70 \mathrm{~kg}$ patient). In old, small, or hemodynamically unstable patients, it may be necessary to start the remifentanil and propofol infusion pumps at 2 to $4 \mathrm{ml} /$ hour.

If the patient is not sufficiently sedated then the propofol infusion is increased by $2 \mathrm{ml} / \mathrm{hour}$, and if the patient complains or exhibits signs of pain then the remifentanil infusion is increased by $2 \mathrm{ml} /$ hour. If the combination of analgesia and sedation is judged 'too deep', then both infusion rates are reduced by $2 \mathrm{ml} /$ hour.

\section{Safety advice}

The nursing staff must be informed that, because of the rapid offset of action, remifentanil syringes must be changed immediately. When the application of remifentanil is finished, the three-way stopcock and infusion line must be flushed. This is necessary to prevent an unintended remifentanil bolus many hours later when the stopcock or infusion line are used again (for instance, for administration of an antibiotic). Furthermore, use of remifentanil in extubated patients is not recommended. All mixtures of remifentanil with infusion fluids should be used immediately.

For propofol it must be emphasized that the propofol syringe must be filled aseptically and immediately before use. Furthermore, the German propofol SmPC recommends that one propofol syringe should not be used for more than 12 hours, and propofol should not be used for more than 7 days in total. In order to prevent a propofol infusion syndrome, we do not use more than $4 \mathrm{mg} / \mathrm{kg}$ per hour of propofol in ICU patients. Because in our departments we only care for adult patients, we have limited the use of propofol $2 \%$ to $10 \mathrm{ml} /$ hour (which equals $200 \mathrm{mg} /$ hour). If a greater dosage is deemed necessary by the nursing staff, then they must consult the ICU physician. If propofol $4 \mathrm{mg} / \mathrm{kg}$ per hour is insufficient for sedation in the ICU patient, then $5 \mathrm{mg}$ bolus doses of midazolam may be added every 4 to 8 hours as needed.

\section{How to introduce remifentanil on the intensive care unit}

It is important to bear in mind that remifentanil is currently licensed for provision of analgesia in mechanically ventilated adult ICU patients for up to 72 hours only. Because of the unique properties of remifentanil, it may be prudent to run the first remifentanil protocols in patients who will probably be ventilated for only a brief period of time (for example, postoperatively). When the entire ICU staff is experienced with the use of remifentanil, further groups of patients can be selected based on the strengths and properties of remifentanil. Examples of such groups include patients with renal or liver impairment, neurologic or neurosurgical patients, patients admitted to the ICU with an unclear diagnosis, and patients in whom weaning and extubation are planned within the next 3 days.

\section{Conclusion}

Although nearly all mechanically ventilated ICU patients require infusions or repeated bolus doses of opioids for pain relief, their use may be associated with multiple problems, the foremost being accumulation and prolonged drug effect. A different approach is to use remifentanil, which is metabolized by unspecific blood and tissue esterases and undergoes rapid metabolism, independent of the duration of infusion or any organ insufficiency. Remifentanil can be used for analgesia and sedation in all kinds of adult ICU patients, either alone or in combination with other sedatives. Furthermore, it has a rapid and predictable offset of effect, potentially allowing either significant reductions in weaning and extubation times or clear differentiation between oversedation and brain dysfunction.

\section{Competing interests}

WW and SK declare that they or their respective departments have received fees and salaries from GlaxoSmithKline for giving lectures about remifentanil. Dr Wilhelm also serves as a paid consultant to GlaxoSmithKline on the use of 
remifentanil on the ICU. Moreover, Dr Wilhelm has given lectures and received fees and salaries from other companies, including AstraZeneca, Baxter, Dräger, Fresenius, and Storz.

\section{Acknowledgement}

Every effort has been made to ensure the correctness of all presented data, such as names of drugs, dosages, applications, and instructions. However, the authors deny responsibility for any case, especially for the possibility of deviations from licensed uses and especially across different countries. Dosages as presented have been applied in adults only and some differ from licenced use. The user has to check all informations for their correctness and individual applicability. Where references to the remifentanil (Ultiva ${ }^{\circledR}$ ) Summary of Product Characteristics (SmPC) or licence are made, these apply to the currently approved EU SmPC (GlaxoSmithKline, April 2007).

This article is part of Critical Care Volume 12 Supplement 3: Analgesia and sedation in the ICU. The full contents of the supplement are available online at http://ccforum.com/supplements/12/S3.

Publication of the supplement has been funded by an unrestricted grant from GlaxoSmithKline.

\section{References}

1. Novaes MA, Knobel E, Bork AM, Pavao OF, Noqueira-Martins LA, Ferraz MB: Stressors in ICU: Perception of the patient, relatives and healthcare team. Intensive Care Med 1999, 25:14211426.

2. Soliman HM, Melot C, Vincent JL: Sedative and analgesic practice in the intensive care unit: the results of a European survey. Br J Anaesth 2001, 87:186-192.

3. Mazoit JX, Butscher K, Samii K: Morphine in postoperative patients: pharmacokinetics and pharmacodynamics of metabolites. Anesth Analg 2007, 105:70-78.

4. Jacobi J, Fraser GL, Coursin DB, Riker RR, Fontaine D, Wittbrodt ET, Chalfin DB, Masica MF, Bjerke HS, Coplin WM, et al.; Task Force of the American College of Critical Care Medicine (ACCM) of the Society of Critical Care Medicine (SCCM), American Society of Health-System Pharmacists (ASHP), American College of Chest Physicians: Clinical practice guidelines for the sustained use of sedatives and analgesics in the critically ill adult. Crit Care Med 2002, 30:119-141.

5. Martin J, Bäsell K, Bürkle H, Hommel J, Huth G, Kessler P, Kretz FJ, Putensen Ch, Quintel M, Tonner $\mathrm{P}$, et al:: Analgesia and sedation in intensive care medicine. S2-Guidelines of the German Society of Anaesthesiology and Intensive Care Medicine. Anästhesiol Intensivmed 2005, 46(Suppl):1-20.

6. Klees TM, Sheffels P, Dale O, Kharasch ED: Metabolism of alfentanil by cytochrome P4503A (CYP3A) enzymes. Drug Metab Dispos 2005, 33:303-311.

7. Kress JP, Pohlman AS, O'Connor MF, Hal JB: Daily interruption of sedative infusions in critically ill patients undergoing mechanical ventilation. $N$ Engl J Med 2000, 342:1471-1477.

8. Kollef MH, Levy NT, Ahrens TS, Schaiff R, Prentice D, Sherman $\mathrm{G}$ : The use of continuous IV sedation is associated with prolongation of mechanical ventilation. Chest 1998, 114:541-548.

9. Rathgeber J, Schorn B, Falk V, Kazmaier S, Spiegel T, Burchardi $\mathrm{H}$ : The influence of controlled mandatory ventilation (CMV), intermittent mandatory ventilation (IMV) and biphasic intermittent positive airway pressure (BIPAP) on duration of intubation and consumption of analgesics and sedatives. A prospective analysis in $\mathbf{5 9 6}$ patients following adult cardiac surgery. Eur J Anaesthesiol 1997, 14:576-582.

10. Egan TD, Lemmens HJ, Fiset P, Hermann DJ, Muir KT, Stanski DR, Shafer SL: The pharmacokinetics of the new short-acting opioid remifentanil (GI87084B) in healthy adult male volunteers. Anesthesiology 1993, 79:881-892.

11. Glass PSA, Gan TJ, Howell S: A review of the pharmacokinetics and pharmacodynamics of remifentanil. Anesth Analg 1999, 89(Suppl):7-14.

12. Cox EH, Langemeijer MWE, Gubbens-Stibbe JM, Muir KT, Danhof $\mathrm{M}$ : The comparative pharmacodynamics of remifentanil and its metabolite, GR90291, in a rat electroencephalographic model. Anesthesiology 1999, 90:535-544.

13. Scott $L$, Perry CM: Remifentanil: a review of its use during the induction and maintenance of general anaesthesia. Drugs 2005, 65:1793-1823.

14. Hoke JF, Shlugman D, Dershwitz M, Michalowski P, MalthouseDufore S, Connors PM, Martel D, Rosow CE, Muir KT, Rubin N, Glass PS: Pharmacokinetics and pharmacodynamics of remifentanil in persons with renal failure compared with healthy volunteers. Anesthesiology 1997, 87:533-541.

15. Pitsiu M, Wilmer A, Bodenham A, Breen D, Bach V, Bonde J, Kessler P, Albrecht S, Fisher G, Kirkham A: Pharmacokinetics of remifentanil and its major metabolite, remifentanil acid, in ICU patients with renal impairment. $\mathrm{Br} J$ Anaesth 2004, 92:493503.

16. Westmoreland CL, Hoke JF, Sebel PS, Hug CC, Muir KT: Pharmacokinetics of remifentanil (GI87084B) and its major metabolite (GI90291) in patients undergoing elective inpatient surgery. Anesthesiology 1993, 79:893-903.

17. Evans TN, Park GR: Remifentanil in the critically ill. Anaesthesia 1997, 52:800-801.

18. Soltész S, Biedler A, Silomon M, Schöpflin I, Molter GP: Recovery after remifentanil and sufentanil for analgesia and sedation of mechanically ventilated patients after trauma or major surgery. Br J Anaesth 2001, 86:763-768.

19. Wilhelm W, Dorscheid E, Schlaich N, Niederprüm, Deller D: The use of remifentanil in critically ill patients. Clinical findings and early experience. Anaesthesist 1999, 48:625-629.

20. Dahaba AA, Grabner T, Rehak PH, List WF, Metzler H. Remifentanil versus morphine analgesia and sedation for mechanically ventilated critically ill patients: a randomized double blind study. Anesthesiology 2004, 101:640-646.

21. Müllejans B, López A, Cross MH, Bonome C, Morrison L, Kirkham AJT: Remifentanil versus fentanyl for analgesia based sedation to provide patient comfort in the intensive care unit: a randomized, double-blind controlled trial. Crit Care 2004, 8: R1-R11.

22. Müllejans B, Matthey T, Scholpp J, Schill M: Sedation in the intensive care unit with remifentanil/propofol versus midazolam/fentanyl: a randomised, open-label, pharmacoeconomic trial. Critical Care 2006, 10:R91.

23. Baillard C, Cohen $Y$, Le Toumelin P, Karoubi P, Hoang P, Ait Kaci F, Cupa M, Fosse JP: Remifentanil-midazolam compared to sufentanil-midazolam for ICU long-term sedation. Ann Fr Anesth Reanim 2005, 24:480-486.

24. Engelhard K, Reeker W, Kochs E, Werner C. Effect of remifentanil on intracranial pressure and cerebral blood flow velocity in patients with head trauma. Acta Anaesthesiol Scand 2004, 48:396-399.

25. Leone M, Albanese J, Viviand X, Garnier F, Bourgoin A, Barrau K, Martin $C$. The effects of remifentanil on endotracheal suctioning-induced increases in intracranial pressure in head-injured patients. Anesth Analg 2004, 99:1193-1198.

26. Karabinis A, Mandragos K, Stergiopoulos S, Komnos A, Soukup J, Speelberg B, Kirkham AJT: Safety and efficacy of analgesiabased sedation using remifentanil versus standard hypnoticbased regimens in intensive care unit patients with brain injuries: a randomised, controlled trial [ISRCTN50308308]. Crit Care 2004, 8:R268-R280.

27. Bauer C, Kreuer S, Ketter R, Grundmann U, Wilhelm W. Remifentanil-propofol versus fentanyl-midazolam combinations for intracranial surgery: Influence of anaesthesia technique and intensive sedation on ventilation times and duration of stay in the ICU. Anaesthesist 2007, 56:128-132.

28. Dershwitz M, Hoke JF, Rosow CE, Michalowski P, Connors PM, Muir KT, Dienstag JL: Pharmacokinetics and pharmacodynamics of remifentanil in volunteer subjects with severe liver disease. Anesthesiology 1996, 84:812-820.

29. Navapurkar VU, Archer S, Gupta SK, Muir KT, Frazer N, Park GR: Metabolism of remifentanil during liver transplantation. $\mathrm{Br} J$ Anaesth 1998, 81:881-886.

30. Breen D, Wilmer A, Bodenham A, Bach V, Bonde J, Kessler P, Albrecht S, Shaikh S: Offset of pharmacodynamic effects and safety of remifentanil in intensive care unit patients with various degrees of renal impairment. Crit Care 2004, 8:R21R30.

31. Breen D, Karabinis A, Malbrain M, Morais R, Albrecht S, Jarnvig IL, 
Parkinson P, Kirkham AJT: Decreased duration of mechanical ventilation when comparing analgesia-based sedation using remifentanil with standard hypnotic-based sedation for up to 10 days in intensive care unit patients: a randomised trial [ISRCTN47583497]. Crit Care 2005, 9:R200-R210.

32. Park G, Lane M, Rogers S, Bassett P. A comparison of hypnotic and analgesic based sedation in a general intensive care unit. $\mathrm{Br} J$ Anaesth 2007, 98:76-82.

33. Wilhelm W, Wrobel M, Kreuer S, Larsen R. Remifentanil: an update. Anaesthetist 2003, 52:473-494.

34. Bouillon T, Kietzmann D, Port R, Meineke I, Hoeft A: Population pharmacokinetics of piritramide in surgical patients. Anesthesiology 1999, 90:7-15.

Disclaime

This article is part of Critical Care Volume 12 Supplement 3: Analgesia and sedation in the ICU. Publication of the supplement has been funded by an unrestricted grant from GlaxoSmithKline. GlaxoSmithKline has had no editorial control in respect of the articles contained in this publication.

The opinions and views expressed in this publication are those of the authors and do not constitute the opinions or recommendations of the publisher or GlaxoSmithKline. Dosages, indications and methods of use for medicinal products referred to in this publication by the authors may reflect their research or clinical experience, or may be derived from professional literature or other sources. Such dosages, indications and methods of use may not reflect the prescribing information for such medicinal products and are not recommended by the publisher or GlaxoSmithKline. Prescribers should consult the prescribing information approved for use in their country before the prescription of any medicinal product.

Whilst every effort is made by the publisher and editorial board to see that no inaccurate or misleading data, opinion, or statement appear in this publication, they wish to make it clear that the data and opinions appearing in the articles herein are the sole responsibility of the contributor concerned.

Accordingly, the publishers, the editor and editorial board, GlaxoSmithKline, and their respective employees, officers and agents accept no liability whatsoever for the consequences of such inaccurate or misleading data, opinion or statement 